\section{Arctic collaboration transcends tensions}

Of all world regions, the Arctic is the most sensitive to climate change and drives feedbacks that amplify the effects of global warming around the planet. Understanding the Arctic relies on developing a better knowledge of the hugely expansive Russian Arctic regions, which offer unique opportunities to study landscape systems across large latitudinal gradients, linked by major river networks.

However, these regions have been something of a blind spot for the international community of Arctic scientists. This is due to access difficulties and to research findings going unrecognized because of language barriers. Happily, at a time of mounting political tension between Russia and the United Kingdom, early-career Arctic scientists from both countries are working together.

Following workshops held in March at Lomonosov Moscow State University and at the British Antarctic Survey in Cambridge, $\mathrm{UK}$, a group of these researchers are now collaborating to remove logistical hurdles and to combine complementary resources and expertise. The workshops were organized by the UK Natural Environment Research Council's Arctic Office, the UK Polar Network, the Association of Polar Early Career Scientists in Russia and the UK Science and Innovation Network.

Immediate challenges include pooling knowledge that is scattered among publications in English or in Russian.

Imminent outcomes include the organization of a conference in the Russian Arctic, a database of funding sources, and guidelines for working in the area (see go.nature.com/2jvdtnk).

This successful collaboration demonstrates how science diplomacy can transcend the hostility of government politics. Such cooperation among earlycareer researchers now should advance scientific and social progress over the decades to

come.

Sammie Buzzard University

College London, UK.

Joseph Cook University of

Sheffield, UK.

Alexey Maslakov Lomonosov

Moscow State University, Russia

s.buzzard@ucl.ac.uk

\section{Road mapping needs AI experts}

As road building expands globally, an automated system for detecting and mapping roads in near-real time is urgently needed to plan land use and conservation management. Machine-learning or artificial-intelligence (AI) specialists must help to meet this formidable challenge.

Current road data are grossly inadequate (see W. F. Laurance et al. Nature 513, 229-232; 2014), and most mapping techniques rely on visual interpretation by humans. Even the communityled OpenStreetMap initiative which aims to maintain accurate maps of roads and many other built features - is patchy and suffers from systematic biases among nations, regions and biomes (www.openstreetmap. org). The freely available, highresolution radar data sets being collected globally in all weather conditions under the European Union's Copernicus Earthobservation programme are an important advance.

What we sorely need now is a road-detection algorithm that can discriminate between paved and unpaved roads. Crucially, it would need to operate consistently under varying topographical and environmental conditions, and be able to distinguish roads from other linear components such as low walls, irrigation ditches and natural features.

A road-detection algorithm would be instrumental in the discovery of illegal roads that are imperilling the world's most vulnerable ecosystems and species. Authorities will then stand a fighting chance of tackling this huge problem

effectively.

William F. Laurance James Cook University, Cairns, Australia. bill.laurance@jcu.edu.au

\section{Circular economy creates new jobs}

Governments are anticipating that people will be displaced from factory and service jobs as intelligent systems are increasingly deployed. Smart environmental enterprises could offer a more sustainable approach than solutions such as universal pay, and provide employment.

In a circular economy

(see www.nature.com/

thecirculareconomy), commercial enterprises that reverse environmental damage, for example, are needed to deliver value in a new guise. This can take the form of a surcharge for certifying improved environmental conditions - for instance, as a result of companies reusing materials from landfill, or cleaning up the environment after manufacturing processes.

As with other start-ups, government support would be essential. Once in motion, these companies could follow their own competitive paths. Such ventures would also encourage sustainability efforts among conventional manufacturers.

We urgently need to apply such business concepts to sustainability. Landfill space is running out and recyclable materials are piling up through a lack of capacity for handling and processing. The proposed enterprises would incorporate design and business-development functions geared to launching products and services based on waste and recyclable materials.

Some business areas and jobs would have to be created because they do not yet exist. For example, we need an effective process for removing microplastics from soil, water and air.

Andrew Kusiak The University of Iowa, Iowa City, USA. andrew-kusiak@uiowa.edu

\section{Happy 250th to a Colombian great}

This year is the 250th anniversary of the birth of the Colombian scientist, inventor, naturalist and astronomer, Francisco José de Caldas, who directed South America's first astronomical observatory, in Bogotá (then in New Granada). In 1816, a Spanish general had Caldas shot in the back for supporting independence of his country from Spain, claiming that "Spain does not need savants". The eminent scientist's legacy proved otherwise.

His pioneering contributions include the invention of the hypsometer for measuring altitude, based on his observation that the boiling temperature of distilled water is proportional to atmospheric pressure. He put this device to good use as a participant in the Botanical Expedition of New Granada (present-day Colombia, Ecuador, Panama and Venezuela), discovering that organisms adapt along altitudinal gradients in tropical ecosystems.

A passion for meteorology led Caldas to publish a paper in 1808 in which he explored the influence of the physical environment on human behaviour (F. J. D. Caldas Semanario Nuevo Reino Granada 22, 200-207; 1808). His weather observations also enabled others to pin down the exact date of a volcanic eruption in the tropics in 1808, which had been suspected from sulfur isotopes in ice cores but was not recorded by eyewitnesses at the time (see A. Guevara-Murua et al. Clim. Past 10, 1707-1722; 2014).

In the end, astronomy was his undoing. His Newtonian views on the Universe were considered heretical in the Spanish colonies at that time. And Caldas used the observatory as a cover for his revolutionary activities. César Marín Austral University of Chile, Valdivia, Chile. cesar.marin@postgrado.uach.cl 